Original Article

\title{
Pattern of Musculoskeletal Disorders in Adult Diabetics patient
}

\author{
Sharmin $\mathrm{S}^{1}$, ${ }^{*}$ Newaz $\mathrm{F}^{2}$, Ahmed $\mathrm{SM}^{3}$, Shahin $\mathrm{A}^{4}$, Hasan $\mathrm{MI}^{5}$, Rahman $\mathrm{HH}^{6}$, Sadeque $\mathrm{Z}^{7}$, Siddique $\mathrm{N}^{8}$
}

\begin{abstract}
Diabetes mellitus is associated with several musculoskeletal (MSK) disorders. Due to increased incidence and life expectancy causes increased prevalence and clinical importance of MSK alterations in diabetic subjects. It is difficult to find out the direct relation with metabolic control. This study was conducted to explore the pattern of musculoskeletal disorders in the diabetic patients. A cross-sectional study was conducted from January' 2016 to June' 2016 at Department of Physical Medicine and Rehabilitation, Bangabandhu Sheikh Mujib Medical University, Dhaka with 190 cases divided in two groups. Patients aged 40-70 years with musculoskeletal disorder with diabetes mellitus (type 2) for five years attending in the department of Physical Medicine and Rehabilitation were included in group A. Patients with MSK disorder without diabetes aged 40-70 years were included in group B. Main
\end{abstract}

1. Dr. Shaila Sharmin, Consultant of Narayangonj Diabetic Hospital

2. *Dr. Fatema Newaz, Consultant, Physical Medicine \& Rehabilitation, LABAID Mymensing, E-mail: washimafatin@gmail.com, Mobile: 01636110089.

3. Dr. Syed Mozaffor Ahmed, Professor, Department of Physical Medicine and Rehabilitation, BSMMU, Dhaka

4. Dr. Abu Shahin, Associate Professor, Department of Rheumatology, BSMMU, Dhaka

5. Dr. Md. Israt Hasan, Medical Officer, Department of Physical Medicine and Rehabilitation, Kurmitola General Hospital, Dhaka

6. Dr. Hasan Habibur Rahman, Medical Officer, Department of Physical Medicine and Rehabilitation, Kurmitola General Hospital, Dhaka

7. Dr. Zafar Sadeque, Medical Officer, Department of Physical Medicine and Rehabilitation, Khulna Medical College and Hospital

8. Dr. Nadia Siddique, Senior Medical Officer, Birdem General Hospital

*For correspondence outcome measures were done by Chi square test and unpaired t test were calculated by using SPSS-20. Out of 190 patients, more than half $(53.68 \%)$ patients were belonged to age 51 60 years in group $A$ and $49(51.58 \%)$ in group $B$. Majority (56.84\%) patients were female in group $A$ and $43(45.26 \%)$ in group $B$. Twenty three $(24.21 \%)$ patients were house wives in group $A$ and 25(26.32\%) in group B. Fifty two (54.73\%) patients had osteoarthritis of knee in group $A$ and $26(27.36 \%)$ in group $B$. Twenty one $(22.11 \%)$ patients had frozen shoulder in group $A$ and $9(9.47 \%)$ in group $B$. Sixteen (16.84\%) patients had Flexor tenosynovitis in group $A$ and 04(4.21\%) in group B. Fifteen (15.78\%) patients had Fibromyalgia in group $A$ and $05(5.26 \%)$ in group $B$. Twelve (12.63\%) patients had Planter fascities in group $A$ and 03(3.16\%) in group B. Which were statistically significant $(p<0.05)$ but other musculoskeletal disorders were not statistically significant $(p>0.05)$ between two groups. More than half patients were belonged to age 51-60 years and female were predominate in both groups. Common musculoskeletal disorders in diabetic patients were osteoarthritis of knee, frozen shoulder, Flexor tenosynovitis, Fibromyalgia, Planter fascities, Rheumatoid arthritis, Carpel tunnel syndrome, Lumbar spondylosis, Cervicalspondylosis and DISH. This study will also be helpful for different organizations working in this area including physiatrist in their program for delivering a comprehensive treatment service. As a result patients were more benefited.

Key word: $M S K$ disorder, DM (Type 2)

\section{INTRODUCTION}

Diabetes mellitus (DM) is a chronic metabolic disease of high morbidity and mortality. ${ }^{1}$ Most common endocrine arthropathies are Musculoskeletal (MSK) complications. ${ }^{2}$ The total population in Bangladesh was recorded 150.5 million people in $2011^{3}$ Type 1 DM results from a complete deficiency of insulin due to the autoimmune-mediated destruction of insulin-producing $\beta$ cells in the pancreas; in type $2 \mathrm{DM}$, which represents most of the DM cases (around 95\%), there is insulin resistance, excessive hepatic production of glucose, and abnormal fat metabolism, resulting in a relative deficiency of that hormone. ${ }^{4-5}$ DM may affect the musculoskeletal system in myriad way. Many rheumatologic disorders have 
been observed more frequently among individuals with DM than in the general population. ${ }^{6}$ The overall connective tissue are affected due to metabolic perturbation. ${ }^{4}$ MSK complications are most commonly seen in patients with a long standing history of type 1 diabetes, but they also may be with type 2 diabetes. ${ }^{7}$ There are three categories of MSK disorders in diabetic patient:

i) Disorders due to intrinsic complications of diabetes like mobility limitation or diabetic cheriarthropathy, muscular infarction, stiff hand syndrome.

ii) Those disorders increases with increased incidence like Adhesive capsulitis, Dupuytren's contracture, osteopenia, neuropathic arthropathy, septic arthritis, Diffuse Idiopathic Skeletal Hyperostosis (DISH) and lastly.

iii) Disorders having possible association with diabetes like carpal tunnel syndrome and osteoarthritis ${ }^{8}$ Common MSK disorders among Bangladeshi diabetic patients studied by Khan et al. are Rheumatoid arthritis, Lumbar spondylosis, Cervical spondylosis, Frozen shoulder, Osteoarthritis of knee joint, Pelvic imflammatory disease, Trigger fingers, Non-specific low back pain, Planter fasciitis, Lateral epicondylitis. ${ }^{9}$ But if it is correctly diagnosed it is usually controllable by the particular handling and management given by a multidisciplinary team work.

\section{MATERIALS AND METHODS}

Diabetes mellitus poses serious health problems both in developed and developing countries. In Bangladesh it is also increasing day by day as like as in whole world ${ }^{10}$. Theprevalence of musculoskeletal disorders in these patients has increased in the recent years affecting significantly their quality of life. Diabetic patients often suffer with many types of musculoskeletal problem like diabetic cheiroarthopathy, or stiff hand syndrome, trigger finger, carpal tunnel syndrome, Dupuytren's contracture, adhesive capsulitis, or frozen shoulder, reflex sympathetic dystrophy charcot's arthropathy, muscular infarction, diffuse idiopathic skeletal hyperostosis, gout, pseudogout, osteoarthritis etc. The prevalence of musculoskeletal disorders generally increases with age. ${ }^{11}$ This study aims to address these problems and design preventive, curative and rehabilitative management for diabetic patients with musculoskeletal disorder. Studies have demonstrated that local and widespread musculoskeletal pains are more common in patients with the type-2 diabetes. These MSK disorders have significant health and safety issues and this is a challenge to better understand major effects on economy and make effective proposal for the prevention and treatment of this disorders. ${ }^{12}$ Patients were included according to similar nutritional, occupational, socioeconomic characteristics to maintain compare between diabetic (group A) and non-diabetic (group B) patients. About 190 patient were taken by purposive sampling and divided into two groups. Patients aged 40-70years with musculoskeletal disorder with diabetes mellitus for five years(type 2) attending in the department of Physical Medicine and Rehabilitation were included in group A. Patients with MSK disorder without diabetes aged 4070 year were included in group B. Patient with diabetes $<5$ years and ages $<40$ and $>70$ years with poor cognition and communication problem and any history/ evidence of infections, recent trauma, fracture, malignancy, tuberculosis etc. were excluded for both groups. Standard questionnaire were used to identify the musculoskeletal complain and collect demographic information. Data were process and analyses using SPSS (Statistical Package for Social Sciences) software version 20. The chi- square test and student " $\mathrm{t}$ " test were used to analyze the significance level of $\mathrm{p}<0.05$. Continuous scale data were presented as mean standard deviation and Categorical data were presented as number percentage. The summarize data were present in the table andchart.

\section{Quality assurance strategy:}

A pretest was done by data sheet before starting the research proper and after that it was finalized. After collecting data it was checked for omission, inadequacy and inconsistency. Omission was corrected by re-taking history or re-examining the patient and discuss with our consultants. Irrelevant and inconsistent data was discarded.

\section{Statistical Methods}

Data were process and analyses using SPSS (Statistical Package for Social Sciences) software version 20. The chisquare test and student " $\mathrm{t}$ " test were used to analyze the significance level of $\mathrm{p}<0.05$. Continuous scale data were presented as mean standard deviation and Categorical data were presented as number percentage. The summarize data were present in the table andchart. 


\section{Patient and public involvement}

Patients were involved in the setting of the research question but they were not involved in the developing plans for design or implementation of the study. No patients were asked to give opinion on interpretation or writing up of the results. There are no plans to disseminate the results of the research to study participants or the relevant patient community.

\section{RESULT}

Table I: Age distribution of the study population

\begin{tabular}{|l|c|c|c|}
\hline Age (years) & $\begin{array}{c}\text { Group-A } \\
\mathrm{n}(\%)\end{array}$ & $\begin{array}{c}\text { Group-B } \\
\mathrm{n}(\%)\end{array}$ & $\begin{array}{c}\mathrm{P} \\
\text { value }\end{array}$ \\
\hline $40-50$ & $28(29.47)$ & $35(36.84)$ & \\
\hline $51-60$ & $51(53.68)$ & $49(51.58)$ & $0.418^{\mathrm{ns}}$ \\
\hline $61-70$ & $16(16.84)$ & $11(11.58)$ & \\
\hline Total & $95(100)$ & $95(100)$ & \\
\hline Mean \pm SD & $48.37 \pm 12.03$ & $46.62 \pm 11.13$ & \\
\hline
\end{tabular}

$\mathrm{ns}=$ not significant

$P$ value reached from chi square test

Group A= Diabetics

Group $B=$ Non diabetics

Table 3.1 shows age distribution of the study population, it was observed that more than half $51(53.68 \%)$ patients were belonged to age 51-60 years in group $A$ and $49(51.58 \%)$ in group $B$. The mean age was $48.37 \pm 12.03$ in diabetes patients and $46.62 \pm 11.13$ years in nondiabetes patients.

\section{Table II: Sex distribution of the study population}

\begin{tabular}{|l|c|c|l|}
\hline Sex & $\begin{array}{c}\text { Group-A } \\
\mathrm{n}(\%)\end{array}$ & $\begin{array}{c}\text { Group-B } \\
\mathrm{n}(\%)\end{array}$ & P value \\
\hline Male & $41(43.16)$ & $52(54.74)$ & $0.110 \mathrm{~ns}$ \\
\hline Female & $54(56.84)$ & $43(45.26)$ & \\
\hline Total & $95(100)$ & $95(100)$ & \\
\hline
\end{tabular}

ns= not significant

$\mathrm{P}$ value reached from chi square test
Table 3.2 shows sex distribution of the study population, it was observed that majority $(56.84 \%)$ patients were female in group A and 43(45.26\%) in group B. The difference was not statistically significant $(\mathrm{p}>0.05)$ between two groups $\square$ aGroup -A aGroup -B

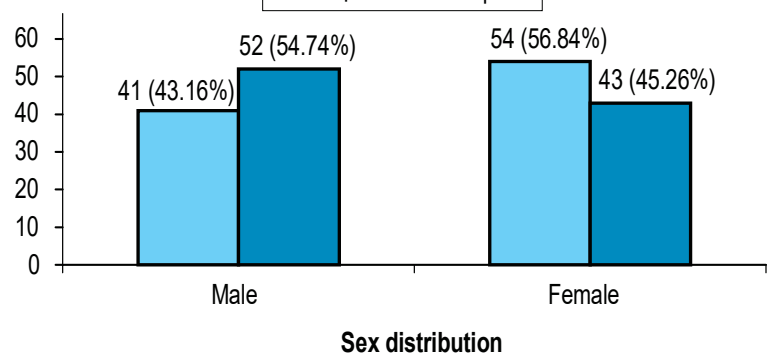

Figure 1: Sex distribution of the study population

Table III Occupational status of study population

\begin{tabular}{|l|c|c|l|}
\hline $\begin{array}{l}\text { Occupational } \\
\text { status }\end{array}$ & $\begin{array}{c}\text { Group-A } \\
\mathrm{n}(\%)\end{array}$ & $\begin{array}{c}\text { Group-B } \\
\mathrm{n}(\%)\end{array}$ & P value \\
\hline House wife & $23(24.21)$ & $25(26.32)$ & \\
\cline { 1 - 3 } Retried & $22(23.16)$ & $17(17.89)$ & \multirow{2}{*}{$0.942 \mathrm{~ns}$} \\
\cline { 1 - 3 } Service & $19(20.00)$ & $21(22.11)$ & \\
\cline { 1 - 3 } Day labor & $9(9.47)$ & $7(7.37)$ & \\
\cline { 1 - 3 } Teacher & $08(8.42)$ & $07(7.37)$ & \\
\cline { 1 - 3 } Farmer & $07(7.37)$ & $8(8.42)$ & \\
\cline { 1 - 3 } Business & $7(7.37)$ & $10(40.53)$ & \\
\hline
\end{tabular}

ns= not significant

$P$ value reached from chi square test

Table 3.3 shows occupational status of the study population, it was observed that $23(24.21 \%)$ patients were house wives in group A and $25(26.32 \%$ ) in group B. Followed by $23.16 \%$ retired in group $\mathrm{A}$ and $17.89 \%$ in group B and 20\% service holder in group A and 22.11\% in group $\mathrm{B}$. The difference was not statistically significant ( $p>0.05)$ between two groups.

Table IV: Socio-economic condition of study population

\begin{tabular}{|l|l|c|l|}
\hline $\begin{array}{l}\text { Socio-economic } \\
\text { Condition }\end{array}$ & $\begin{array}{l}\text { Group-A } \\
\mathrm{n}(\%)\end{array}$ & $\begin{array}{c}\text { Group-B } \\
\mathrm{n}(\%)\end{array}$ & P value \\
\hline Poor & $21(22.11)$ & $30(31.58)$ & \\
\hline Middle & $62(65.26)$ & $51(53.68)$ & $0.245 \mathrm{~ns}$ \\
\hline Rich & $12(12.63)$ & $14(14.74)$ & \\
\hline
\end{tabular}

ns= not significant

$P$ value reached from chi square test 
Table IV: Socio-economic condition of study population

\begin{tabular}{|l|l|l|l|}
\hline $\begin{array}{l}\text { Socio-economic } \\
\text { Condition }\end{array}$ & $\begin{array}{c}\text { Group-A } \\
\mathrm{n}(\%)\end{array}$ & $\begin{array}{c}\text { Group-B } \\
\mathrm{n}(\%)\end{array}$ & P value \\
\hline Poor & $21(22.11)$ & $30(31.58)$ & \\
\hline Middle & $62(65.26)$ & $51(53.68)$ & $0.245 \mathrm{~ns}$ \\
\hline Rich & $12(12.63)$ & $14(14.74)$ & \\
\hline
\end{tabular}

ns= not significant

$P$ value reached from chi square test

Source: HIES 2005

Notes: (i) The socio-economic status of the study patients $(\mathrm{n}=190)$ were determined assuming the income stated by the patients as follows: (BBS-HIES:2010)13

\begin{tabular}{|l|l|l|}
\hline Poor & -Monthly income & $\mathrm{Tk}<8000 /$ - \\
\hline Middle class & -Monthly income & $\mathrm{Tk} 8000 /$ - to 20,000/- \\
\hline Rich & -Monthly income & $\mathrm{Tk}>20,000 /$ - \\
\hline
\end{tabular}

Table IV shows socio-economic status of the study population, it was observed that almost two third (65.26\%) of the patients come from middle class family in group A and 51(53.68\%) in group B. The difference was not statistically significant $(p>0.05)$ between two groups.
Table V: Height, weight and BMI of study population

\begin{tabular}{|l|c|c|l|}
\hline & $\begin{array}{c}\text { Group-A } \\
\text { Mean }( \pm S D)\end{array}$ & $\begin{array}{c}\text { Group-B } \\
\text { Mean }( \pm S D)\end{array}$ & P value \\
\hline Height (inch) & $5.39( \pm 0.28)$ & $5.31( \pm 0.34)$ & $0.078 \mathrm{~ns}$ \\
\hline Weight $(\mathrm{kg})$ & $59.22( \pm 8.83)$ & $56.97( \pm 8.02)$ & $0.067 \mathrm{~ns}$ \\
\hline BMI $(\mathrm{kg} / \mathrm{m} 2)$ & $24.2( \pm 2.9)$ & $23.4( \pm 3.2)$ & $0.073 \mathrm{~ns}$ \\
\hline
\end{tabular}

ns= not significant

$\mathrm{P}$ value reached from unpaired t-test

Mean height was found $5.39( \pm 0.28)$ inches in group A and $5.31( \pm 0.34)$ inches in group-B. The mean weight was found $59.22( \pm 8.83) \mathrm{kg}$ in group A and $56.97( \pm 8.02) \mathrm{kg}$ in group-B. The mean BMI was found $24.2( \pm 2.9) \mathrm{kg} / \mathrm{m} 2$ in group $A$ and $23.4( \pm 3.2) \mathrm{kg} / \mathrm{m} 2$ in group- $\mathrm{B}$. The difference were not statistically significant $(\mathrm{p}>0.05)$ between two groups.

Fifty two $(54.73 \%)$ patients had osteoarthritis of knee in group A and 26(27.36\%) in group B. Twenty one $(22.11 \%)$ patients had frozen shoulder in group A and $9(9.47 \%)$ in group B. Sixteen (16.84\%) patients had Flexor tenosynovitis in group A and $04(4.21 \%)$ in group B. Fifteen $(15.78 \%)$ patients had Fibromyalgia in group A and 05(5.26\%) in group B. Twelve (12.63\%) patients had Planter fascities in group A and $03(3.16 \%)$ in group $B$. Which were statistically significant $(\mathrm{p}<0.05)$ but other musculoskeletal disorders were not statistically significant $(\mathrm{p}>0.05)$ between two groups.

Table VI: Common musculoskeletal disorders of study population

\begin{tabular}{|l|c|c|c|c|}
\hline Musculoskeletal disorders & Group-A n(\%) & Group-B $\mathrm{n}(\%)$ & Total & $\mathrm{p}$ value \\
\hline Osteoarthritis of knee & $52(54.73)$ & $26(27.36)$ & 78 & $0.001 \mathrm{~s}$ \\
\hline Frozen shoulder & $21(22.11)$ & $9(9.47)$ & 30 & $0.017 \mathrm{~s}$ \\
\hline Lumbar spondylosis & $19(20.00)$ & $11(11.58)$ & 30 & $0.111 \mathrm{~ns}$ \\
\hline Rheumatoid arthritis & $17(17.89)$ & $21(22.11)$ & 38 & $0.468 \mathrm{~ns}$ \\
\hline Flexor tenosynovitis & $16(16.84)$ & $04(4.21)$ & 20 & $0.009 \mathrm{~s}$ \\
\hline Cervical spondylosis & $15(15.79)$ & $12(12.63)$ & 27 & $0.533 \mathrm{~ns}$ \\
\hline Fibromyalgia & $15(15.78)$ & $05(5.26)$ & 20 & $0.018 \mathrm{~s}$ \\
\hline Planter fascities & $12(12.63)$ & $03(3.16)$ & 15 & $0.015 \mathrm{~s}$ \\
\hline Carpel tunnel syndrome & $09(9.47)$ & $04(4.21)$ & 18 & $0.150 \mathrm{~ns}$ \\
\hline Osteoporosis & $07(7.37)$ & $02(2.11)$ & 09 & $0.087 \mathrm{~ns}$ \\
\hline DISH & $05(5.26)$ & $1(1.05)$ & 06 & $0.080 \mathrm{~ns}$ \\
\hline Dupuytren's contracture & $05(5.26)$ & $01(1.05)$ & 06 & $0.097 \mathrm{~ns}$ \\
\hline Lateral Epicondylitys & $03(3.16)$ & $02(2.11)$ & 05 & $0.650 \mathrm{~ns}$ \\
\hline
\end{tabular}

$s=$ significant, $\mathrm{ns}=$ not significant

$P$ value reached from chi square test 


\section{DISCUSSION}

This cross sectional study was carried out in the Department of Physical Medicine and Rehabilitation, Bangabandhu Sheikh Mujib Medical University, Dhaka. During six month of study period, total 190 samples were included in this study, among them 95 diabetic patients were purposely selected those who have diabetes for $>5$ years in group A and 95 were non diabetics in group B.

In this present study it was observed that more than half $51(53.68 \%)$ of patients were belonged to age 51-60 years in group $\mathrm{A}$ and $49(51.58 \%)$ in group $\mathrm{B}$. The mean age was $48.37 \pm 12.03$ years in diabetes patients and $46.62 \pm 11.13$ years in non-diabetes patients. Similar observation was found in a study of Rahim et al. ${ }^{13}$ they showed mean age was found $48.87 \pm 12.03$ year in diabetes group and $43.26 \pm 12.73$ years in non-diabetes group. One of the biggest medical centers in Northern Taiwan studied by Wang et al. ${ }^{14}$ observed that the mean age was $56.24 \pm 9.17$ year in non-diabetes group whereas $55.19 \pm 8.41$ years in diabetes group that is approximately similar to our study. In contrast a Bangladeshi study by Khan et al. ${ }^{9}$ observed out of 2062 patients, $31.9 \%$ were between the age group of 41-50 years and 29.8\% was between 51-60years.

Majority $54(56.84 \%)$ of the female patients belongs to group A and 43(45.26\%) in group B in this study whereas $52(54.74 \%)$ male patients belongs to group B and $41(43.16 \%)$ in group A. Similar observation was found Barki et al. ${ }^{16}$ showed that in diabetes mellitus, $158(42.1 \%)$ patients were males and $217(57.9 \%)$ were females. Wang et al. ${ }^{14}$ study showed $26(61.9 \%)$ patients were female in non-diabetes group and 14(66.66\%) in diabetes group. Khan et al. ${ }^{12}$ studied total of 2062 patients with MSK disorders. Out of them 927 (44.9\%) were males and 1135 $(55.1 \%)$ were females which is also similar to our study. In study of Rahim et al. ${ }^{13}$ seventeen patients were male in diabetes and 297 in non-diabetes group that all observations support our study.

In this study it was observed that $23(56.84 \%)$ patients were house wives in diabetics group 25(26.32\%) in non-diabetics group followed by $23.16 \%$ retired parsons in diabetics group and $17.89 \%$ in non-diabetics group, $20 \%$ service holders in diabetics group and $22.11 \%$ in non-diabetics group. Similar observation was found Khan et al. ${ }^{9}$ majority were

House-wives $(56.5 \%)$ followed by retired servicemen (16.3\%), service holders (13.8\%), businessmen $(7.4 \%)$ and teachers $(2.3 \%)$. Another study Roy ${ }^{17}, 6 \%$ are service holder, $1 \%$ are banker, $9 \%$ are teacher, $27 \%$ are housewife, $23 \%$ are businessman, $4 \%$ are job in the private farm, $4 \%$ are job in the NGO, $11 \%$ are driver, $13 \%$ are retired and $1 \%$ job in the other sector that results also support ourstudy.

The study showed that the mean height was found $5.39 \pm 0.28$ inch in group $A$ and $5.31 \pm 0.34$ inch in group- $B$. The mean weight was found $59.22 \pm 8.83 \mathrm{~kg}$ in group $\mathrm{A}$ and $56.97 \pm 8.02 \mathrm{~kg}$ in group-B. The mean BMI was found $24.2 \pm 2.9 \mathrm{~kg} / \mathrm{m}^{2}$ in group $A$ and $23.4 \pm 3.2$ $\mathrm{kg} / \mathrm{m}^{2}$ in group-B. The difference were not statistically significant $(p>0.05)$ between two groups. In Barki et al.16 study showed normal BMI was found 141(44\%) in type 2 DM. Everson SA et al. ${ }^{14}$ the mean BMI was found $24.06 \pm 3.67 \mathrm{~kg} / \mathrm{m}^{2}$ in non-diabetes group and $24.79 \pm 2.58$ $\mathrm{kg} / \mathrm{m}^{2}$ in diabetes group. The mean BMI was not statistically significant ( $>0.05$ ) between the two groups. Roy ${ }^{17}$ study observed body weight was found $30-40 \mathrm{~kg}$ (1\%), 41-50kg (6\%), 51-60kg (44\%), and 61-70kg (47\%), 71-80kg (3\%)and 81-90kg (1\%).

In this series osteoarthritis of Knee was found 52(54.73\%) in diabetes group and 26(27.36\%) in non-diabetes group. Similar observation was found in study of Nieves-Plaza et al. ${ }^{18}$ in 2013 reported OA among diabetics patients was $49.0 \%$, whereas in non- diabetics subjects OA was $26.5 \%$ $(\mathrm{p}<0.01)$. But in contrast in Bangladeshi study by Khan et al. ${ }^{9} 2008$ reported $8.1 \%$ Osteoarthritis of knee joint in diabetes patients. The discrepancy could be due to our study includes majority of patients aged 51-60 years and Osteoarthritis of knee is more common in elderly.

Frozen shoulder was found $21(22.11 \%)$ in diabetes group and $9(9.47 \%)$ in non-diabetes group in this study. In study by Khan et al. ${ }^{9} 2008$ reported $16.5 \%$ Frozen shoulder in diabetes patients. Umesh and Ranganatha ${ }^{19}$ study in 2014 showed the most common findings were frozen shoulder in diabetes patients which was $18 \%$, that is nearly similar to our study. But in contrast, results of Roy showed in diabetes patients $8 \%$ are frozen shoulder. The difference could be due to they studied referred as accidental, volunteer or opportunistic sampling.

From the results of the present study Lumbar spondylosis was found in diabetes patients 21(22.11\%) and $11(11.58 \%)$ were in non-diabetes group. The findings of present study have similarity with the findings of Khan et al. ${ }^{9}$ who reported $19.1 \%$ Lumbar spondylosis in diabetes patients. In study of Asadian et al. ${ }^{20}$ studied in 2016 they found 29.1\% Lumbar spondylosis in diabetespatients. 
The study revealed that $17(17.89 \%)$ Rheumatoid arthritis was diagnosed in diabetes patients and $21(22.11 \%)$ was in non-diabetes patients. In study of Khan et al. had similar observation they showed $20.1 \%$ Rheumatoid arthritis in diabetes group. Dubreuil $M$ et al concluded that the observed association between patients with RA and incident type 2 diabetes could substantially explained by obesity and lifestyle factors ${ }^{21}$

In this study, $16(16.84 \%)$ Flexor tenosynovitis was diagnosed in diabetics patients and 04(4.21\%) in non-diabetics patients. Trigger finger has been shown to have a prevalence of approximately $20 \%$ in multiple studies of diabetics populations, compared with roughly $2 \%$ in the generalpopulation. ${ }^{15,22,23}$

Cervical spondylosis was found $15(15.79 \%)$ in diabetes patients and $12(12.63 \%)$ in non diabetes patients in this study. In Khan et $\mathrm{al}^{9}$ study observed $18.3 \%$ Cervical spondylosis was found in diabetes that results is support to our study.

In this study showed Fibromyalgia 15(15.78\%) in diabeticss and 5(5.26\%) in non diabeticss. Tishler et al.24 study showed Fibromyalgia was diagnosed in $17 \%$ with $\mathrm{DM}$ and in $2 \%$ healthy control $(\mathrm{P}=0.008)$. Wolak et al. ${ }^{25}$ assessed 137 patients with type 2 diabetes mellitus and a control group of 139 patients matched for age and sex that do not suffer from diabetes mellitus. Among the men of both groups no difference in prevalence was seen. But in case of diabetic women they had a significantly higher prevalence of fibromyalgia than women in the control group: $23.3 \%$ versus $10.6 \%$ respectively $(\mathrm{p}=0.043)$.

In this study $12(12.63 \%)$ planter fascities was found in diabetes group and $03(3.16 \%)$ was in non-diabetes group. Narreddy and Reddy ${ }^{26}$ studied in 2015 found higher than our study which was $21(70 \%)$ planter fascities in diabetics patients. The higher percentage could be due to they studied only obese patients.

Carpel tunnel syndrome was diagnosed 09 (9.47\%) in diabetes patients. In Becker's study, DM was a risk factor for CTS. In Kidwai's study the presence of limited joint mobility, CTS, trigger finger and Dupuytren's contracture were higher in diabetics patients ${ }^{27}$ Perkins et al. ${ }^{28}$ study showed 14\% Carpel tunnel syndrome in diabetics patients. The incidence of carpal tunnel syndrome in the diabetics population has consistently been reported as between $11 \%$ and $21 \%$, in numerousstudies. ${ }^{15,29}$
Osteoporosis was diagnosed $07(7.37 \%)$ in diabetics and $02(2.11 \%)$ in non-diabetics patients. Leidig-Bruckner et al. ${ }^{30}$ the prevalence of osteoporosis at the Lumber Spondylosis was $6.1 \%$ in men and $9.4 \%$ in women with type 2 diabetes which is agreement with our present study. Another study in china 2013 reported 33.3\% Osteoporosis in diabetes patients. ${ }^{31}$ This was done in hospitalized patients in the Department of Endocrinology who are above 60 years. The discrepancy could be due to our study patients were between $40-70$ years and most of them were below 60 .

In this study DISH was diagnosed 5(5.26\%) in diabetics and $1(1.05 \%)$ in non-diabeties. A study in Turkey Sencan et al. ${ }^{32}$ reported that DISH (12\%) was higher in patients with DM than the control group $(6.8 \%)$, but there was no statistically significant difference.

About 5 (5.26\%) patients in present study have Dupuytren's contracture. Fitzgibbons and Weiss ${ }^{33}$ study found that diabetes mellitus in their population of Dupuytren's contracture patients was only slightly higher than in the general population (11 vs. $7 \%$ ). Dupuytren's contracture in diabeties patient's ranges from 20 to $63 \%$ that observation was not supported our study. The discrepancy could be due to they include only the patients with Dupuytren's contracture and studied 20 years ago, ${ }^{23,34}$ The finding of $5.26 \%$ cases of Dupuytren's contracture indicates that it is not uncommon in our country.

In this study $03(3.16 \%)$ Lateral Epicondylitys in diabetes patients and $02(2.11 \%)$ in non diabetes patients. Shiri et al. ${ }^{35}$ study reported 6\% Lateral Epicondylitys in type 2 diabetes patients.

\section{CONCLUSION}

Diabetes mellitus has been associated with a number of musculoskeletal manifestations. Common musculoskeletal disorders in diabetic patients were osteoarthritis of knee, frozen shoulder, Flexor tenosynovitis, Fibromyalgia, Planter fascities, Rheumatoid arthritis, Carpel tunnel syndrome, Lumbar spondylosis, Cervical spondylosis and DISH. Identification and treatment of those lesions are important to improve the patients' quality of life. On the other hand, knowing those associations might enable the diagnosis of DM in patients not yet recognized as such, and, thus, lead to the institution of proper therapy that will prevent the development of diabeticcomplications. 


\section{Limitations of the study}

1. The study population was selected from one selected hospital in Dhaka city, so that the results of the study may not be reflect the exact picture of thecountry.

2. The present study was conducted at a very short period oftime.

3. Small sample size was also a limitation of the present study. Therefore, in future further study may be under taken with large samplesize.

\section{CONTRIBUTORS:}

SS and FN designed the study. HHR, MIH, ZS analysed the data. ZS and NS drafted the figure and the tables. SS, FN drafted the manuscript, and all the authors read, revised the manuscript, and approved its final version. HHR and MIH are responsible for the overall content as guarantors, and accept full responsibility for the work and the conduct of the study, had access to the data, and controlled the decision to publish. Funding: This study was not supported any funding. We confirm that the researchers were independent from funders and that all authors had full access to all of the data (including statistical reports and tables) in the study. Disclosure: No other authors have same interest. Ethical approval: In this study, keeping compliance with Helsinki Declaration for Medical Research Involving Human Subjects 1964, the nature and purpose of the study was informed in detail to all participants. Voluntary participations were encouraged. There was no physical, psychological and social risk to the subjects. Informed and understood written consent was taken from every patient before enrollment. Privacy, anonymity and confidentiality of data information identifying any patient were maintained strictly. Each patient was enjoyed every right to participate or refuse or even withdrawn from the study at any point of time. Before starting this study ethical clearance was taken from Institutional Review Board (IRB) of BSMMU.

Data taken from the participants were coded and regarded as confidential and kept locked under investigator for purposeful use only. This protocol primary selected by academic committee of Department of Physical Medicine and Rehabilitation. Due respect was given to all the subjects.

\section{RECOMMENDATIONS}

Further studies can be undertaken by including large number of patients with multi- centered approach.

\section{REFERENCES}

1. Silva MBG, Skare TL. Musculoskeletal disorders in diabetes mellitus. Rev Bras Reumatol, 2012; 52(4): 594-609.

2. Egede LE. Diabetes, major depression, and functional disability among U.S. adults. Diabetes Care, 2004; 27:421-8.

3. World Bank. South Asia at Health cross roads with high rates of heart disease, diabetes and obesity. World Bank publications and document. http://go. World Bank.org/ IYWVBWY950 [Accessed on 24 June 2012].

4. Labiedz-Odrobina D, Kay J. Rheumatic manifestations of diabetes mellitus. Theum Dis Clim North Am, 2010; 36:681-699.

5. Power AC. Diabetes mellitus. In: Kasper DL, Braunwald E, Fauci A, Hauser S, Longo D Jameson JL (eds). Harrison's Principle of Internal Medicine. 16th ed. McGraw-Hill, 2004:3779-829.

6. Crispin JC, Alcocer-Varela J. Rheumarologic manifestations of diabetes mellitus. Am J Med, 2003; 114:753-757.

7. Burner TW, Rosenthal AK. Diabetes and rheumatic diseases. Curr Opin Rheumatol, 2009; 20:500-54.

8. Khan MSZ, Shakoor MA, Moyeenuzzaman M, Islam MQ. Pattern of musculoskeletal disorders among diabetic patients attending a tertiary care hospital in Dhaka. Ibrahim Med Coll J, 2008; 2(2): 65-66.

9. Ahmad I, Nadeem D, Aziz A. Musculoskeletal disorder in long-standing DM Cases. JPOA, 2008; 20(1): 38 .

10. Tabish SA. Is diabetes becoming the biggest epidemic of the twenty-first century?. International Journal of health sciences. 2007 Jul;1(2):V.Seaman Dr. Body mass index and musculoskeletal pain: is there a connection. Chiropractic and manual therapies, 2013; 21: 1-15.

11. Barki S, Khan HM, Jilani SM, Nooruddin $M$. Common Musculosekeltal Disorders in Diabetes Mellitus Patients. Pak J Rehabil. 2013; 2(1):53-62.

12. Rahim MA, Rahman MI, Mostafa AW, Ahmed SF. The Prevalence Rate of Diabetes Mellitus (DM) in Rural Population of Bangladesh. Dinajpur Medical College Journal, 2011; 4(2):41-48.

13. Income H. Expenditure Survey, HIES (2010). Preliminary Report on Household Income \& Expenditure Survey: Statistics Division, Ministry of Planning. The Government of the People's Republic of Bangladesh. 2014. 
14. Everson SA, Maty SC, Lynch JW, Kaplan GA. Epidemiologic evidence for the relation between socioeconomic status and depression, obesity, and diabetes. Journal of psychosomatic research. 2002 Oct 1;53(4):891-5.

15. Chammas M, Bousquet P, Renard E, Poirier J, Jaffiol C, Allieu Y. Dupuytren's disease, carpal tunnel syndrome, trigger finger, and diabetes mellitus. Journal of Hand Surgery in America, 1995; 20:109-114.

16. Barki S, Khan HM, Jilani SM, Nooruddin M. Common Musculosekeltal Disorders in Diabetes Mellitus Patients. Pak J Rehabil. 2013; 2(1):53-62.

17. Roy A. Common musculoskeletal disorders among the diabetic patients attended at Birdem General Hospital in Dhaka. Bachelor of Science in Physiotherapy, 2013: 1-71.

18. Nieves-Plaza M, Castro-Santana LE, Font YM, Mayor AM, Vilá LM. Association of hand or knee osteoarthritis with diabetes mellitus in a population of Hispanics from Puerto Rico. J Clin Rheumatol 2013; 19(1):10.1097.

19. Umesh KS, Ranganatha YP. Musculoskeletal and Joint Manifestations in Type II Diabetes Mellitus. AJADD 2015; 3(1):059-063.

20. Asadian L, Haddadi K, Aarabi M, Zare A. Diabetes Mellitus, a New Risk Factor for Lumbar Spinal Stenosis: A Case-Control Study. Endocrinology and Diabetes 2016:9 1-5.

21. Dubreuil M, Rho YH, Man A, Zhu Y, Zhang Y Diabetes incidence in psoriatic arthritis, psoriasis and rheumatoid arthritis: a UK population-based cohort study. Rheumatology 2013; 53:346-352.

22. Starkman HS, Gleason RE, Rand LI, Miller DE, Soeldner JS. Limited joint mobility (LJM) of the hand in patients with diabetes mellitus: relation to chronic complications. Ann Rheum Dis 1986; 45: $130-135$.

23. Jennings AM, Milner PC, Ward JD. Hand abnormalities are associated with the complications of diabetes in type 2 diabetes. Diabet Med 1989; 6: 43- 47.

24. Tishler M, Smorodin T, Vazina-Amit M, Ramot Y, Koffler M, Fishel B. Fibromyalgia in diabetes mellitus. Rheumatol Int 2003; 23(4): 171-3.
25. Wolak T, Weitzman S, Harman-Boehm I,Friger M, Sukenik S. Prevalence of fibromyalgia in type 2 diabetes mellitus. Harefuah 2001; 140(11):1006-9

26. Narreddy JS and Reddy VS. Prevalence of plantar fasciitis and calcaneal spurs in obese diabetics - a cross sectional study. R 2015; 2(8):31-34

27. Becker J, Nora B, Gomes I, Stringari FF, Seitensus R, Panosso JS, et al. An evaluation of gender, obesity, age and diabetes mellitus as risk factors for carpal tunnel syndrome. Clin Neurophysiol 2002; 113(9): 1429-34.

28. Perkins BA, Olaleye D, Bril V. Carpal Tunnel Syndrome in Patients with Diabetic Polyneuropathy. Diabetes Care 2002; 25(3):565-569.

29. Singh R, Gamble G, Cundy T. Lifetime risk of symptomatic carpal tunnel syndrome in type 1 diabetes. Diabet Med 2005; 22: 625-630.

30. Leidig-Bruckner G, Grobholz S, Bruckner T, ScheidtNave C, Nawroth Pand Schneide JG. Prevalence and determinants of osteoporosis in patients with type 1 and type 2 diabetes mellitus. BMC Endocrine Disorders 2014; 14:33:2-13

31. Shan PF, Wu XP, Zhang H, Cao XZ, Gu W, Deng $\mathrm{XG}, \mathrm{Gu} \mathrm{C}$, Liao EY. Bone mineral density and its relationship with body mass index in postmenopausal women with type 2 diabetes mellitus in mainland China. Journal of bone and mineral metabolism. 2009 Mar 1; 27(2):190-7.

32. Sencan D, Elden H, Nacitarhan V, Sencan M, Kaptanoglu E. The prevalence of diffuse idiopathic skeletal hyperostosis in patients with diabetes mellitus. Rheumatol Int 2005; 25(7):518-21.

33. Fitzgibbons PG, Weiss AP. Hand manifestations of diabetes mellitus. The Journal of hand surgery. 2008 May 1;33(5):771-5.

34. Forgacs SS. Diabetes mellitus and rheumatic disease. Clin Rheum Dis 1986; 12: 729-53.

35. Shiri R, Viikari-Juntura E, Varonen H, Helio vaara M. Prevalence and Determinants of Lateral and Medial Epicondylitis: A Population Study. Am J Epidemiol 2006; 164:1065-1074. 